\title{
Right Ventricular Myocardial Oxygen Partial Pressure Is Reduced in Monocrotaline-induced Pulmonary Hypertension in the Rat and Restored by Myo-inositol Trispyrophosphate
}

\author{
Marta Oknińska \\ Centre of Postgraduate Medical Education
}

\section{Zuzanna Zambrowska}

Centre of Postgraduate Medical Education

Karolina Zajda

Military Medical Institute

\section{Aleksandra Paterek}

Centre of Postgraduate Medical Education

Klaudia Brodaczewska

Military Medical Institute

\section{Urszula Mackiewicz}

Centre of Postgraduate Medical Education

\section{Cezary Szczylik}

Centre of Postgraduate Medical Education

\section{Adam Torbicki}

Centre of Postgraduate Medical Education

\section{Claudine Kieda}

Military Medical Institute

Michał Mączewski ( $\nabla$ michal.maczewski@cmkp.edu.pl)

Centre of Postgraduate Medical Education

\section{Research Article}

Keywords: pulmonary arterial hypertension, monocrotaline, oxygen, right ventricular function, hypoxia, myo-inositol trispyrophosphate (ITPP)

Posted Date: June 3rd, 2021

DOI: https://doi.org/10.21203/rs.3.rs-572950/v1

License: (c) (i) This work is licensed under a Creative Commons Attribution 4.0 International License. Read Full License 


\section{Abstract}

Pulmonary arterial hypertension (PAH) initially results in compensatory RV hypertrophy, but eventually in RV failure. This transition is poorly understood, but may be triggered by hypoxia. Measurements of RV oxygen tension $\left(\mathrm{pO}_{2}\right)$ in $\mathrm{PAH}$ are lacking. We hypothesized that RV hypoxia occurs in monocrotaline-induced PAH in rats and that myo-inositol trispyrophosphate (ITPP), facilitating oxygen dissociation from hemoglobin, can relieve it.

Rats received monocrotaline (PAH) or saline (control) and 24 days later echocardiograms, pressure-volume loops were obtained and myocardial $\mathrm{pO}_{2}$ was measured using a fluorescent probe.

In PAH mean pulmonary artery pressure more than doubled ( $35 \pm 5$ vs. $15 \pm 2$ in control), RV was hypertrophied, though its contractility was augmented. $\mathrm{RV}$ and $\mathrm{LV} \mathrm{pO} \mathrm{O}_{2}$ was $32 \pm 5$ and $15 \pm 8 \mathrm{mmHg}$, respectively, in control rats. In $\mathrm{PAH} \mathrm{RV} \mathrm{pO}_{2}$ was reduced to $18 \pm 9 \mathrm{mmHg}$, while $\mathrm{LV} \mathrm{pO} \mathrm{P}_{2}$ was unchanged. $\mathrm{RV} \mathrm{pO}_{2}$ correlated with $\mathrm{RV}$ diastolic wall stress (negatively) and LV systolic pressure (positively). Acute ITPP administration did not affect $\mathrm{RV}$ or $\mathrm{LV} \mathrm{pO} 2$ in control animals, but increased $\mathrm{RV}$ $\mathrm{pO}_{2}$ to $26 \pm 5 \mathrm{mmHg}$ without affecting $\mathrm{LV} \mathrm{pO} 2$ in $\mathrm{PAH}$.

RV oxygen balance is impaired in PAH and as such can be an important target for PAH therapy. ITPP may be one of such potential therapies.

\section{Introduction}

Pulmonary arterial hypertension (PAH) is a condition involving increased pulmonary vascular resistance (PVR) that results in increased mean pulmonary artery pressure (mPAP) and afterload of the cardiac right ventricle (RV). This initially results in compensatory RV hypertrophy, but when RV is no longer able to compensate for the increased afterload, eventually RV failure occurs resulting in patient's death [1].

The cause of this transition from compensatory RV hypertrophy to decompensated RV failure is unclear [2]. Several lines of evidence indicate that impaired RV metabolism [3] and in particular RV hypoxia, i.e. reduced myocardial oxygen tension, may underlie this phenomenon [4, 5]. First, in PAH oxygen delivery is impaired due to increased extravascular compression of RV coronary vessels (due to both RV hypertrophy and increased RV pressures) and reduced coronary perfusion pressure (due to reduced aortic pressure as a consequence of reduced LV cardiac output). Second, increased RV afterload results in proportionally increased energy demand. Third, capillary rarefaction was found in various animal PAH models as well as in humans [6]. Fourth, these changes are accompanied by adverse metabolic reprogramming [7]. Fifth, increased activation of right ventricular hypoxia-inducible factor-1 (HIF-1) pathway, a marker of tissue hypoxia, was found in various models of PAH [8].

However, direct measurements of RV myocardial oxygen content are lacking due to technical difficulties. Indirect methods, utilizing e.g. ${ }^{1} \mathrm{H}$ NMR techniques which estimate the ratio of deoxygenated to oxygenated myoglobin or magnetic resonance imaging based on differences in magnetic properties between oxygenated and deoxygenated hemoglobin [9] exhibit poor specificity and spatial resolution, but indeed suggest that $\mathrm{RV}$ oxygen partial pressure $\left(\mathrm{pO}_{2}\right)$ may be reduced in humans with PAH. However, some studies suggest normal RV oxygen availability [10], while other studies indicate the presence of so called pseudohypoxia, i.e. activation of hypoxia-dependent molecular pathways without true tissue hypoxia [11].

Recently myo-inositol tris-pyrophosphate (ITPP), a novel membrane-permeant allosteric effector of hemoglobin has been developed to enhance the oxygen release capacity of red blood cells specifically under hypoxic conditions [12]. ITPP lowers the affinity of hemoglobin for oxygen, thus counteracting the effects of hypoxia [13]. We have previously shown that ITPP shifts the oxygen dissociation curve downward, therefore increasing tissue oxygen delivery, increases oxygen 
delivery to hypoxic tumors [14], and reduces HIF-1 expression by vascular endothelial cells [15]. This is accompanied by a potent anti-cancer effect in various tumor models in the mouse $[14,16]$. Moreover, we have recently shown that chronic ITPP treatment partially prevents post-myocardial infarction heart failure in the rat model [17]. However effects of ITPP on myocardial $\mathrm{pO}_{2}$ have never been studied.

Thus the aim of our study was to verify the hypothesis that RV is hypoxic in the rat model of monocrotaline (MCT)induced PAH and that acute ITPP administration is able to relieve it. For this purpose we used a specific fluorescencebased method to directly measure myocardial $\mathrm{pO}_{2}$ in situ in $\mathrm{PAH}$ and assess the effects of ITPP treatment.

\section{Methods}

Forty four male Wistar rats, weighing 180-220 g, were used. All study animals were used in compliance with local and institutional regulations. The study conformed to the Guide for the Care and Use of Laboratory Animals, US National Institutes of Health (NIH Publication No. 85-23, revised 1996) and was approved by the local ethics committee (Second Warsaw Local Ethics Committee for Animal Experimentation). The manuscript follows the recommendations in the ARRIVE guidelines. ITPP was a kind gift from professor Jean-Marie Lehn, UNISTRA, University of Strasbourg to CK.

\section{Study protocol}

At the age of 4-5 weeks the rats received a subcutaneous injection of MCT (60 mg/ $\mathrm{kg}$, Sigma) to induce pulmonary hypertension $(n=26)$ or saline $(n=18)$ as a control group. Twenty four days later the animals from both control $(n=13)$ and MCT $(n=14)$ groups were anesthetized using inhaled $2 \%$ isoflurane, underwent echocardiographic examination, followed by hemodynamic evaluation and $\mathrm{pO}_{2}$ measurements. Thereafter they were euthanized and their lungs were processed for histological examination.

The remaining animals from the control $(n=5)$ and MCT $(n=5)$ groups underwent echocardiographic examination, received a single intraperitoneal dose of ITPP (1.5 g/ kg b.wt.) and 1 hour later were re-anesthetized, underwent echocardiographic examination, followed by hemodynamic evaluation and $\mathrm{pO}_{2}$ measurements. Thereafter they were euthanized and their lungs were processed for histological examination. A total of 7 rats died in the MCT group, while there were no deaths in the control group.

\section{Echocardiographic evaluation}

Transthoracic echocardiography was performed using E-cube 15 Platinum (Alpinion Medical Systems) with $17 \mathrm{MHz}$ linear transducer under a light isoflurane sedation. The rats were placed on a heating pad to sustain proper body temperature. Images of the parasternal short-axis view (SAX) at the papillary muscle level, parasternal long axis view (PLAX) and the apical 4-chamber view $(4 \mathrm{CH})$ were. LV and RV fractional shortening as well as LV and RV diastolic and systolic wall thickness were assessed using the M-mode in PLAX view. All measurements were obtained by one observer blinded to the study groups.

\section{Hemodynamic evaluation}

As reported previously [18], rats were put on a heating pad, anesthetized with $2 \%$ isoflurane, intubated and put on an animal ventilator. The upper abdominal cavity was opened and the heart was exposed through cutting of the diaphragm. The left ventricular and subsequently right ventricular apex was punctured with a $25 \mathrm{G}$ needle and a microtip pressurevolume (PV) catheter (SPR-838, Millar Instruments; Houston, TX) was inserted into the LV. Its position was established based on pressure and volume signals. After stabilization for 5 minutes, the signals were continuously recorded at sampling rate of 1000/s using an ARIA P-V conductance system (Millar Instruments) coupled to a PowerLab/4SP A/D converter (AD Instruments; Mountain View, CA) and a personal computer. To characterize cardiac function, first the inferior 
vena cava was compressed for 10 seconds and then released to achieve reduction and augmentation of venous return and cardiac preload, respectively. Heart rate, maximal LV and RV systolic pressure (ESP), end-diastolic pressure (EDP), maximal slope of systolic pressure increment $(+\mathrm{dP} / \mathrm{d} t$ max) and diastolic pressure decrement (-dP/dt max), ejection fraction (EF), end-diastolic volume (EDV), end-systolic volume (ESV), stroke volume (SV), and cardiac output (CO) were computed using a cardiac P-V analysis program (PVAN3.2, Millar Instruments). Indexes of contractility and stiffness [slope of end-systolic and end-diastolic P-V relations (ESPVR and EDPVR)] were also calculated using PVAN3.2.

\section{4. $\mathrm{pO}_{2}$ measurements}

Myocardial tissue $\mathrm{pO}_{2}$ was measured using a fiberoptic oxygen-sensing device, the OxyLite Pro $\mathrm{pO}_{2}$ monitor (Oxford Optronics Ltd., Oxford, UK). This device measures $\mathrm{pO}_{2}$ by determining the oxygen-dependent fluorescent lifetime of ruthenium chloride. Probes are supplied precalibrated by the manufacturer. The tip of an optical fiber probe is covered with ruthenium chloride, which fluorescence lifetime is $\mathrm{O}_{2}$-dependent and is inversely proportional to the $\mathrm{pO}_{2}$ in the tissue. Following excitation by a flash of green light, the measured half-life of the phosphorescence signal can be quantitatively related to the oxygen tension.

The rats were anesthetized using inhaled isoflurane (2\%) and connected to a ventilator. The heart was exposed by leftsided thoracotomy, and a 20-gauge needle was used to pierce the epicardium and guide the probe into the myocardium immediately beneath the epicardium. A 100- $\mu \mathrm{m}$ diameter sensing tip was inserted into three locations in the cardiac RV and LV as well as in the liver and spleen. The p02 signal was recorded until the signal was stable. Subsequently data were averaged for each location.

Under baseline conditions the animals were mechanically ventilated with $30-40 \%$ inspiration oxygen, which is above the ambient air content of oxygen (21\%) with spontaneously breathing. The higher inspiration oxygen levels are necessary to compensate for the known ventilation-perfusion defects caused by anesthesia and mechanical ventilation, especially in diseased animals. Mechanical ventilation with a $\mathrm{FiO}_{2}$ of $21 \%$ resulted in an arterial tension of approximately $80 \mathrm{mmHg}$, below the $100 \mathrm{mmHg}$ normally obtained with spontaneous breathing, indicating that the use of ambient air oxygen levels with mechanical ventilation and anesthesia was indeed associated with insufficient blood oxygenation [10]. Finally 100\% oxygen was used to ventilate the rat lungs and the $\mathrm{pO}_{2}$ measurements were repeated.

\section{Histological lung analysis}

The lungs were inflated with OCT (Optimal Cutting Temperature) compound and then placed in plastic molds filled with OCT and snap-frozen in liquid nitrogen. All tissues were maintained at $-80^{\circ} \mathrm{C}$ until further analysis.

The representative lung parts were cut into $5 \mu \mathrm{m}$-thick sections using Cryostat Microm HM550 (Thermo Fisher Scientific, Massachusetts, USA) and stained with the hematoxylin and eosin (H\&E) stain for microscopic analysis. Arterioles with an external diameter of 30-90 $\mu \mathrm{m}$ were assessed and \% wall thickness was expressed as (2xwall thickness / external vessel diameter).

\section{Statistical analysis}

Shapiro-Wilk test was used to test normality of data distribution. Homogeneity of variances was tested by Bartlett's. Normally distributed data were expressed as means \pm SEM. One-way ANOVA was used to test differences between groups. Tukey post hoc test was used to compare data pairs. Non-normally distributed data were presented as median \pm inter-quartile ranges + outliers. Subsequently statistical analysis of differences was tested using non-parametric methods (Mann-Whitney test to compare two groups or Kruskal-Wallis ANOVA to compare three or more groups followed by Dunn's post hoc test). Pearson correlation analysis was used to analyze the correlations. Differences were considered significant when $P<0.05$. Statistical analyses were performed using SigmaPlot version 14 . 


\section{Results}

\section{Pulmonary hypertension - the model}

Twenty four days after MCT injection rats demonstrated significant hypertrophy of pulmonary arterioles (\% wall thickness $16.7 \pm 4.5 \%$ vs. $23.4 \pm 5.0 \%$ in control rats, $p<0.05$; Fig. $1 \mathrm{~A}$ and $1 \mathrm{~B}$ ) and consequently increased pulmonary vascular resistance (PVR, Fig. 1C) and mean pulmonary artery pressure (mPAP, Fig. 1D), revealing typical chain of events for PAH.

RV was dilated, which was reflected by increased RV end-diastolic volume (RVEDV, Fig. 1E-H Fig. 2A-B), while LVEDV was reduced (Fig. 1E-H, Fig. 2A-B). Normalized right ventricular (RV) mass (Table 1) and RV diastolic wall thickness (Fig. 2C) were increased by $50 \%$, while the corresponding parameters for LV were unchanged in PAH rats. 
Table 1

Morphological and hemodynamic characteristics of monocrotaline- and saline-treated rats

\begin{tabular}{|c|c|c|c|c|c|c|c|c|c|c|c|}
\hline & $\begin{array}{l}\text { control } \\
(n= \\
13)\end{array}$ & SD & $\begin{array}{l}\text { MCT } \\
(n= \\
14)\end{array}$ & SD & $\begin{array}{l}p< \\
0.05\end{array}$ & & $\begin{array}{l}\text { control } \\
(n= \\
13)\end{array}$ & SD & $\begin{array}{l}\text { MCT } \\
(n= \\
14)\end{array}$ & SD & $\begin{array}{l}p< \\
0.05\end{array}$ \\
\hline $\begin{array}{l}\text { Body } \\
\text { weight, g }\end{array}$ & 341 & 10 & 305 & 12 & * & Normalized & & & & & \\
\hline $\begin{array}{l}\text { Heart } \\
\text { weight, g }\end{array}$ & 0.94 & 0.05 & 0.96 & 0.06 & & & 2.76 & 0.21 & 3.15 & 0.24 & \\
\hline $\begin{array}{l}\text { LV weight, } \\
\text { g }\end{array}$ & 0.61 & 0.02 & 0.51 & 0.03 & * & & 1.79 & 0.06 & 1.67 & 0.11 & \\
\hline $\begin{array}{l}\text { RV weight, } \\
\text { g }\end{array}$ & 0.19 & 0.02 & 0.25 & 0.02 & * & & 0.56 & 0.08 & 0.82 & 0.09 & * \\
\hline RV/LV & 0.31 & 0.03 & 0.49 & 0.03 & * & & & & & & \\
\hline $\begin{array}{l}\text { Lung } \\
\text { weight, g }\end{array}$ & 2.30 & 0.38 & 3.04 & 0.34 & * & & 6.74 & 1.11 & 9.97 & 1.16 & * \\
\hline $\begin{array}{l}\text { Left } \\
\text { ventricle }\end{array}$ & & & & & & $\begin{array}{l}\text { Right } \\
\text { ventricle }\end{array}$ & & & & & \\
\hline HR (bpm) & 450 & 18 & 411 & 25 & & & 444 & 22 & 408 & 26 & \\
\hline $\begin{array}{l}\text { CO } \\
(\mu \mathrm{l} / \mathrm{min})\end{array}$ & 43485 & 5447 & 34527 & 2732 & * & & 47185 & 8329 & 29504 & 4073 & * \\
\hline EF (\%) & 59.9 & 2.1 & 65.7 & 2.7 & & & 53.9 & 1.3 & 27.4 & 4.1 & * \\
\hline $\begin{array}{l}\mathrm{ESP} \\
(\mathrm{mmHg})\end{array}$ & 119.8 & 2.2 & 86.0 & 16.7 & * & & 27.3 & 1.5 & 71.5 & 3.6 & * \\
\hline $\begin{array}{l}\text { EDP } \\
(\mathrm{mmHg})\end{array}$ & 7.6 & 1.9 & 5.4 & 0.2 & & & 6.0 & 0.0 & 9.5 & 1.0 & * \\
\hline $\begin{array}{l}\mathrm{dp} / \mathrm{dtmax} \\
(\mathrm{mmHg} / \mathrm{s})\end{array}$ & 10306 & 1776 & 8727 & 1300 & & & 2289 & 79 & 3074 & 124 & * \\
\hline $\begin{array}{l}\mathrm{dp} / \mathrm{dtmin} \\
(\mathrm{mmHg} / \mathrm{s})\end{array}$ & -6620 & 946 & -4026 & 854 & * & & -1250 & 154 & -2047 & 94 & * \\
\hline $\begin{array}{l}\text { ESPVR } \\
(\mathrm{mmHg} / \\
\mu \mathrm{l})\end{array}$ & 1.32 & 0.11 & 1.31 & 0.12 & & & 0.17 & 0.02 & 0.48 & 0.04 & * \\
\hline $\begin{array}{l}\mathrm{Ea} \\
(\mathrm{mmHg} / \\
\mu \mathrm{l})\end{array}$ & 0.98 & 0.07 & 0.95 & 0.06 & & & 0.23 & 0.04 & 0.70 & 0.11 & * \\
\hline ESPVR/Ea & 0.74 & 0.07 & 0.74 & 0.07 & & & 0.74 & 0.09 & 0.69 & 0.09 & \\
\hline $\begin{array}{l}\text { Diastolic } \\
\text { wall } \\
\text { stress } \\
(\mathrm{mmHg})\end{array}$ & 9.85 & 1.56 & 6.24 & 1.11 & * & & 8.94 & 1.43 & 19.91 & 9.92 & * \\
\hline $\begin{array}{l}\text { Systolic } \\
\text { wall } \\
\text { stress } \\
(\mathrm{mmHg})\end{array}$ & 168.68 & 11.84 & 105.76 & 26.75 & * & & 36.68 & 3.47 & 125.24 & 51.42 & * \\
\hline
\end{tabular}


Ventricular function was characterized using echocardiography and pressure-volume (PV) loops. RV fractional shortening (FS, Fig. 2D) and ejection fraction (EF, Table 1) were impaired and RV PV loops were shifted to the right (Fig. 1E-H). Consequently cardiac output was reduced by $29 \%$ (Table 1 ).

However, maximum rate of RV pressure increase ( $\mathrm{RV} \mathrm{dP/dt}$ max) was slightly increased, while the most precise and loadindependent index of contractility, slope of end-systolic pressure-volume relation (ESPVR) was increased by almost 3-fold (Table 1), indicating that RV contractility was actually augmented in our model and impairment of EF and FS was due to increased afterload. RV hypertrophy was not sufficient to prevent increase of RV wall stress: the diastolic wall stress was more than doubled, while the systolic wall stress - more than tripled (Table 1).

On the other hand, LV was unloaded and a result of reduced RV function, resulting in leftward and downward shift of LV PV loops (Fig. 1H) and a low grade reduction of LV diastolic and systolic wall stress (Table 1).

\section{Myocardial oxygen content}

Mean myocardial $\mathrm{pO}_{2}$ was $32 \pm 5 \mathrm{mmHg}$ and $15 \pm 8 \mathrm{mmHg}$ in RV and LV (Fig. 3A-D), respectively, in the control animals, while that in the liver and spleen was $19 \pm 11$ and $15 \pm 11 \mathrm{mmHg}$, respectively. Breathing with $100 \%$ oxygen did not affect these values (Fig. 3A-D).

In $\mathrm{PAH}$ animals mean $\mathrm{RV} \mathrm{pO} 2$ was reduced by $44 \%$ to $18 \pm 9 \mathrm{mmHg}$, while $\mathrm{LV} \mathrm{pO}_{2}$ was unchanged $(11 \pm 8 \mathrm{mmHg})$. $\mathrm{pO}_{2}$ values in the liver and spleen were not affected $(14 \pm 8$ and $23 \pm 11 \mathrm{mmHg}$, respectively). Breathing with $100 \%$ oxygen increased $\mathrm{pO}_{2}$ values in $\mathrm{RV}$ to $25 \pm 5 \mathrm{mmHg}$ without affecting $\mathrm{LV} \mathrm{pO}_{2}$ values.

Myocardial oxygen delivery depends on 2 crucial factors, perfusion pressure and vascular resistance. Therefore, to gain insight into potential causes of this reduction of $\mathrm{RV} \mathrm{pO}_{2}$ we correlated myocardial $\mathrm{pO}_{2}$ with LV systolic pressure (LVSP, as a measure of aortic pressure, supplying perfusion pressure to coronary arteries) and with RV wall stress (as a marker of external vascular compression). As Fig. $3 \mathrm{~F}$ and $3 \mathrm{H}$ show, $\mathrm{RV} \mathrm{pO}_{2}$ was highly negatively correlated with $\mathrm{RV}$ diastolic wall stress and positively correlated with LVSP. No such correlation was found for the $\mathrm{LV} \mathrm{pO}_{2}$ values (Fig. $3 \mathrm{G}$ and $3 \mathrm{I}$ ).

\section{Effect of ITPP}

In additional experiments $(n=5)$ a single dose of ITPP was given intraperitoneally and 1 hour later $\mathrm{pO}_{2}$ measurements were performed.

ITPP had no effect on $\mathrm{pO}_{2}$ values in the control animals: both LV and RV (Fig. 3D) as well as hepatic and splenic (not shown) oxygen partial pressures were not affected. $100 \%$ oxygen breathing had no effect in this setting, either. However, in $\mathrm{PAH}$ animals, $\mathrm{RV} \mathrm{pO}_{2}$ was significantly increased by acute ITPP administration by $44 \%$ to $26 \pm 5 \mathrm{mmHg}$. ITPP did not affect $\mathrm{pO}_{2}$ values in the LV (Fig. 3E) or spleen or liver (not shown). $100 \%$ oxygen did not affect $\mathrm{RV} \mathrm{pO}_{2}$ values in MCT-treated rats that received ITPP.

\section{Discussion}

In this paper we reveal two new crucial facts regarding myocardial oxygen partial pressure in a rat model of monocrotaline-induced $\mathrm{PH}$ : (1) we demonstrate that $\mathrm{PAH}$ is associated with reduced $\mathrm{RV} \mathrm{pO}_{2}$ and that this reduction correlates with both reduced LV systolic pressure and increased RV diastolic wall stress and that (2) a new agent, ITPP, that increases oxygen dissociation from hemoglobin, improves $\mathrm{RV} \mathrm{pO}_{2}$ in $\mathrm{PAH}$ without affecting it in the healthy $\mathrm{RV}$ or LV. 


\section{RV function and structure in our pulmonary arterial hypertension model}

In our model of MCT-induced PAH, RV exhibited augmented contractile function as manifested by more than 3-fold increase of ESPVR and marked hypertrophy and dilation corresponding to a compensated stage of RV hypertrophy required to overcome more than 4 -fold increase of RV afterload. However, this was accompanied by reduction of cardiac output that in turn reduced LV preload and its output, resulting in decreased LV pressures and afterload. Thus, paradoxically RV wall stress increased, LV wall stress decreased and RV wall stresses were higher than those in LV, unlike in normal hearts.

\section{RV myocardial oxygen content}

Here we used direct myocardial $\mathrm{pO}_{2}$ measurements utilizing a novel fluoroscopic method. Briefly the system uses a ruthenium chloride fluorescent compound immobilized in a polymer at the tip of a fiber-optic probe, which is $100 \mu \mathrm{m}$ in diameter. Green light produced by diodes within the unit is propagated down the optical fiber to the tip, where it excites the ruthenium chloride. The lifetime of the resultant fluorescence is inversely proportional to the amount of oxygen at the circular area with a diameter of $230 \mu \mathrm{m}$ around the tip. Thus this method offers great spatial resolution.

Here we showed that $\mathrm{RV} \mathrm{pO}_{2}$ was more than 2-fold higher than $\mathrm{LV} \mathrm{pO}_{2}(32 \pm 5 \mathrm{mmHg}$ and $15 \pm 8 \mathrm{mmHg}$, respectively) in control rats. These values for LV are within the ranges reported by other authors and obtained using different methods: 45 $\mathrm{mmHg}$ in the LV of humans undergoing bypass surgery using voltammetric microelectrode technique [19], $35 \mathrm{mmHg}$ of mitochondrial $\mathrm{O}_{2}$ in the rat LV [20], $10 \mathrm{mmHg}$ in the rat LV [21] and $8.6 \mathrm{mmHg}$ in the swine LV using electron paramagnetic resonance oximetry [22]. These results indicate that $\mathrm{LV} \mathrm{pO}_{2}$ values in the literature vary considerably and are probably method-dependent.

However, we are the first to report that $\mathrm{RV} \mathrm{pO}_{2}$ is markedly higher than $\mathrm{LV} \mathrm{pO}_{2}$ in control animals. It has long been known that the $\mathrm{pO}_{2}$ in the veins draining $\mathrm{RV}$ is higher than in those draining LV [23] and that $\mathrm{O}_{2}$ extraction is higher in the LV than in the RV [23]. As RV oxygen consumption increases from rest to exercise, the initial effect is an increasing oxygen extraction (indicated by the falling venous oxygen tension). This increased oxygen extraction in the RV occurs with little change in flow when venous tension is above $10-12 \mathrm{mmHg}$. Conversely, in the LV increases in myocardial oxygen consumption result in negligible decreases in venous oxygen tension and large increases in coronary flow [23]. Our data nicely support these observations, indicating that indeed resting myocardial $\mathrm{pO}_{2}$ is much higher in $\mathrm{RV}$ than in LV. Higher extravascular compression in LV than in RV may be responsible for this phenomenon [24].

Furthermore we showed here that $\mathrm{RV} \mathrm{pO}_{2}$ was reduced by more than $40 \%$ in $\mathrm{PAH}$, while that in the LV was unchanged. This reduction correlated with both indices of reduced perfusion pressure (LVESP) as well as with indices of extravascular compression and oxygen utilization (RV wall stress). Thus it is difficult to determine, which of these factors was the main culprit here. Of note, no such correlation was found for LV p02.

\section{Effects of ITPP on myocardial oxygen}

Affinity of hemoglobin for molecular oxygen is regulated in human red blood cells by 2,3-diphospho-D-glycerate II (DPG), an allosteric effector of hemoglobin. ITPP binds to the same allosteric pocket, resulting in rightward shift of hemoglobin$\mathrm{O}_{2}$ dissociation curve, especially under low $\mathrm{O}_{2}$ conditions [12], which could explain its specific effects found in hypoxic tumor tissues [14]. Moreover, ITPP enters red blood cells through the Band3 transporter, which distribution is mainly restricted to erythrocytes, which is responsible for its red blood cell specific affinity $[13,15]$.

Here we showed that ITTP increased $\mathrm{RV} \mathrm{pO} \mathrm{O}_{2}$ in the PAH rats. What is interesting, $\mathrm{RV} \mathrm{pO}$ in PAH rats (18 mmHg) was still higher than $\mathrm{LV} \mathrm{pO}_{2}$ both in control rats $(15 \mathrm{mmHg})$ and $\mathrm{PAH}$ rats $(14 \mathrm{mmHg})$. However, acute administration of a single 
dose of ITPP improved only $\mathrm{RV} \mathrm{pO}_{2}$ in PAH rats (to $26 \mathrm{mmHg}$ ), without affecting $\mathrm{LV} \mathrm{pO}_{2}$. This again stresses the fact that oxygen supply and utilization is differently regulated in RV and LV and what is acceptable for LV, is hypoxic for RV. This may be due to different density of mitochondria and capillaries between these two ventricles [10], but factors responsible for these differences remain unknown.

\section{Conclusions}

We show that $\mathrm{RV} \mathrm{pO}_{2}$ is markedly reduced in the rat model of MCT-induced PAH and that a new agent, ITPP, that facilitates oxygen release from hemoglobin pecifically under hypoxic conditions, is able to restore it upon acute administration. This indicates that RV is indeed hypoxic in PAH and oxygen supply and more broadly RV energetics can be an important target for PAH therapy; ITPP may be one of such potential therapies. Future studies are needed to verify this hypothesis.

\section{Declarations}

\section{Acknowledgements:}

The authors thank Professor Jean-Marie Lehn, ISIS, University of Strasbourg, 8 Allée Gaspard Monge, 67083 Strasbourg, France and Professor Claude Nicolau, Friedman School of Nutrition Science and Policy, Tufts University Boston, MA 02115, USA, for their constant collaboration, interest and support.

\section{Funding:}

The study was supported by the National Science Centre, Poland Grant No. (2019/35/B/NZ5/04432)

\section{Competing interests statement:}

CK is a shareholder of Normoxys Inc., manufacturer of ITPP. The other authors have no conflicts of interest to disclose.

\section{Availability of data and material:}

All data are available at the Department of Clinical Physiology, Centre of Postgraduate Medical Education, Warsaw, Poland

\section{References}

1. Thenappan, T., Ormiston, M. L., Ryan, J. J. \& Archer, S. L. Pulmonary arterial hypertension: pathogenesis and clinical management. BMJ 360, j5492-j5492, doi:10.1136/bmj.j5492 (2018).

2. Ryan, J. J. \& Archer, S. L. The right ventricle in pulmonary arterial hypertension: disorders of metabolism, angiogenesis and adrenergic signaling in right ventricular failure. Circulation Research 115, 176-188, doi:10.1161/CIRCRESAHA.113.301129 (2014).

3. Koop, A. M. C. et al. Metabolic Remodeling in the Pressure-Loaded Right Ventricle: Shifts in Glucose and Fatty Acid Metabolism - A Systematic Review and Meta-Analysis. Journal of the American Heart Association 8, e012086, doi:doi:10.1161/JAHA.119.012086 (2019).

4. Asosingh, K. \& Erzurum, S. Mechanisms of right heart disease in pulmonary hypertension (2017 Grover Conference Series). Pulm Circ 8, 2045893217753121, doi:10.1177/2045893217753121 (2018).

5. Gómez, A. et al. Right ventricular ischemia in patients with primary pulmonary hypertension. Journal of the American College of Cardiology 38, 1137-1142, doi:https://doi.org/10.1016/S0735-1097(01)01496-6 (2001). 
6. Ruiter, G. et al. Right ventricular oxygen supply parameters are decreased in human and experimental pulmonary hypertension. The Journal of heart and lung transplantation : the official publication of the International Society for Heart Transplantation 32, 231-240, doi:10.1016/j.healun.2012.09.025 (2013).

7. Oikawa, M. et al. Increased [18F]Fluorodeoxyglucose Accumulation in Right Ventricular Free Wall in Patients With Pulmonary Hypertension and the Effect of Epoprostenol. Journal of the American College of Cardiology 45, 18491855, doi:https://doi.org/10.1016/j.jacc.2005.02.065 (2005).

8. Pullamsetti, S. S., Mamazhakypov, A., Weissmann, N., Seeger, W. \& Savai, R. Hypoxia-inducible factor signaling in pulmonary hypertension. The Journal of Clinical Investigation 130, 5638-5651, doi:10.1172/JCI137558 (2020).

9. Sree Raman, K. et al. Right ventricular myocardial deoxygenation in patients with pulmonary artery hypertension. Journal of Cardiovascular Magnetic Resonance 23, 22, doi:10.1186/s12968-020-00694-0 (2021).

10. Balestra, G. M. et al. Increased in vivo mitochondrial oxygenation with right ventricular failure induced by pulmonary arterial hypertension: mitochondrial inhibition as driver of cardiac failure? Respiratory research 16, 6-6, doi:10.1186/s12931-015-0178-6 (2015).

11. Ryan, J. J. \& Archer, S. L. Emerging Concepts in the Molecular Basis of Pulmonary Arterial Hypertension. Circulation 131, 1691-1702, doi:doi:10.1161/CIRCULATIONAHA.114.006979 (2015).

12. Fylaktakidou, K. C., Lehn, J.-M., Greferath, R. \& Nicolau, C. Inositol tripyrophosphate: a new membrane permeant allosteric effector of haemoglobin. Bioorganic \& Medicinal Chemistry Letters 15, 1605-1608, doi:https://doi.org/10.1016/j.bmcl.2005.01.064 (2005).

13. Duarte, C. D., Greferath , R., Nicolau , C. \& Lehn, J.-M. myo-Inositol Trispyrophosphate: A Novel Allosteric Effector of Hemoglobin with High Permeation Selectivity across the Red Blood Cell Plasma Membrane. ChemBioChem 11, 25432548, doi:10.1002/cbic.201000499 (2010).

14. Kieda, C. et al. Stable tumor vessel normalization with $\mathrm{pO}(2)$ increase and endothelial PTEN activation by inositol trispyrophosphate brings novel tumor treatment. Journal of Molecular Medicine (Berlin, Germany) 91, 883-899, doi:10.1007/s00109-013-0992-6 (2013).

15. Kieda, C. et al. Suppression of hypoxia-induced HIF-1alpha and of angiogenesis in endothelial cells by myo-inositol trispyrophosphate-treated erythrocytes. Proc Natl Acad Sci U S A 103, 15576-15581, doi:10.1073/pnas.0607109103 (2006).

16. El Hafny-Rahbi, B. et al. Tumour angiogenesis normalized by myo-inositol trispyrophosphate alleviates hypoxia in the microenvironment and promotes antitumor immune response. Journal of cellular and molecular medicine 25, 32843299, doi:10.1111/jcmm.16399 (2021).

17. Oknińska, M. et al. Treatment of hypoxia-dependent cardiovascular diseases by myo-inositol tris pyrophosphate (ITPP) through enhancement of oxygen delivery by red blood cells. Journal of Cellular and Molecular Medicine 24, 2272-2283, doi:10.1111/jcmm.14909 (2020).

18. Paterek, A. et al. Acute Heart Rate-Dependent Hemodynamic Function of the Heart in the Post-Myocardial Infarction Rat Model: Change Over Time. Canadian Journal of Cardiology 34, 1341-1349, doi:10.1016/j.cjca.2018.08.009 (2018).

19. Al-Obaidi, M. K., Etherington, P. J., Barron, D. J., Winlove, C. P. \& Pepper, J. R. Myocardial tissue oxygen supply and utilization during coronary artery bypass surgery: evidence of microvascular no-reflow. Clinical science (London, England : 1979) 98, 321-328 (2000).

20. Mik, E. G. et al. Mitochondrial oxygen tension within the heart. J Mol Cell Cardiol 46, 943-951, doi:10.1016/j.yjmcc.2009.02.002 (2009).

21. Tokunaga, C. et al. Albumin resuscitation improves ventricular contractility and myocardial tissue oxygenation in rat endotoxemia*. Critical Care Medicine 35, 1341-1347, doi:10.1097/01.ccm.0000260242.77637.57 (2007). 
22. Zhao, X. et al. Endothelium-derived nitric oxide regulates postischemic myocardial oxygenation and oxygen consumption by modulation of mitochondrial electron transport. Circulation 111, 2966-2972, doi:10.1161/circulationaha.104.527226 (2005).

23. Tune, J. D., Gorman, M. W. \& Feigl, E. O. Matching coronary blood flow to myocardial oxygen consumption. Journal of Applied Physiology 97, 404-415, doi:10.1152/japplphysiol.01345.2003 (2004).

24. Cai, Z. et al. Right ventricular oxygen delivery as a determinant of right ventricular functional reserve during exercise in juvenile swine with chronic pulmonary hypertension. American Journal of Physiology-Heart and Circulatory Physiology 317, H840-H850, doi:10.1152/ajpheart.00130.2019 (2019).

\section{Figures}

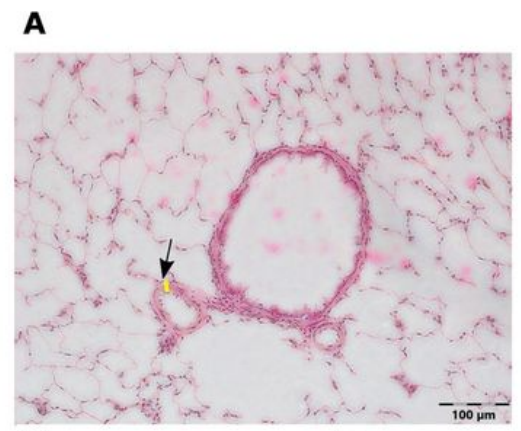

c

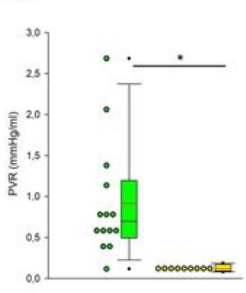

$\mathbf{F}$

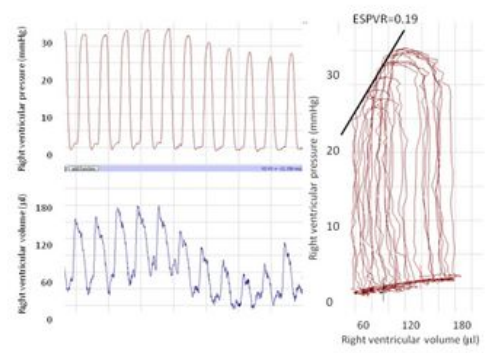

B

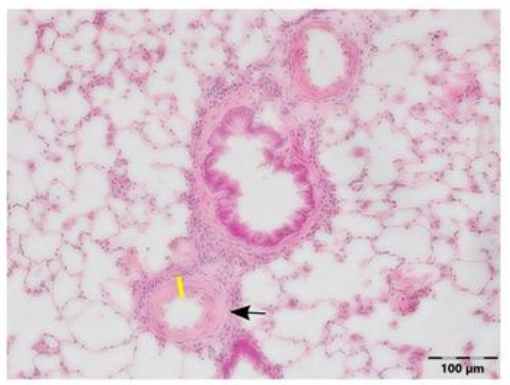

$\mathbf{E}$

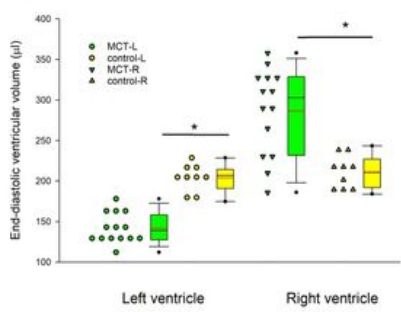

G

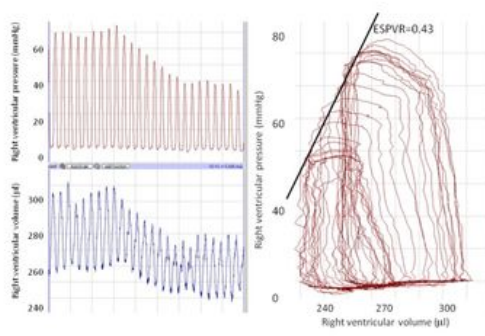

\section{H}

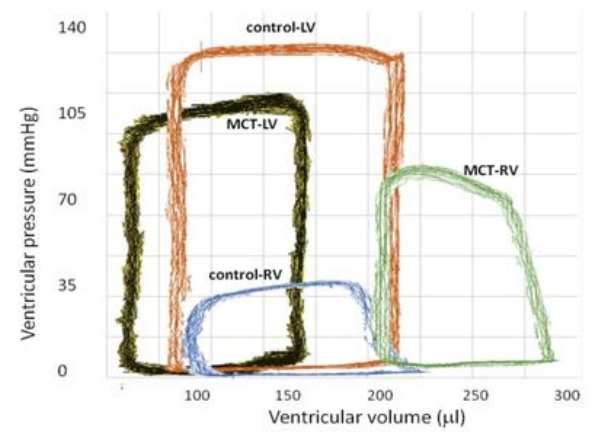

Figure 1 
Histological and hemodynamic characterization of rats with monocrotaline-induced pulmonary hypertension and control rats. Representative hematoxylin and eosin stained images from control (A) and monocrotaline (MCT)-treated (B) rats, demonstrating small pulmonary arterioles (arrows). Yellow bars indicate arteriolar wall thickness. Clear wall thickening and luminal stenosis can be seen in a MCT rat. (C) demonstrates pulmonary vascular resistance (PVR), (D) mean pulmonary artery pressure (mPAP), and (E) left and right ventricular end-diastolic volumes. Representative right ventricular pressure-volume loops and tracings of right ventricular pressure and volumes are presented for control (F) and MCT (G) rats. $(H)$ presents representative RV and LV PV loops from control and MCT rats. Horizontal lines represent mean (red) and median (black), the bottom and the top of the boxes represent the upper and the lower quartile, he whiskers represent 10th and 90th percentile, while the solid circles represent the individual data points. * $p<0.05$.
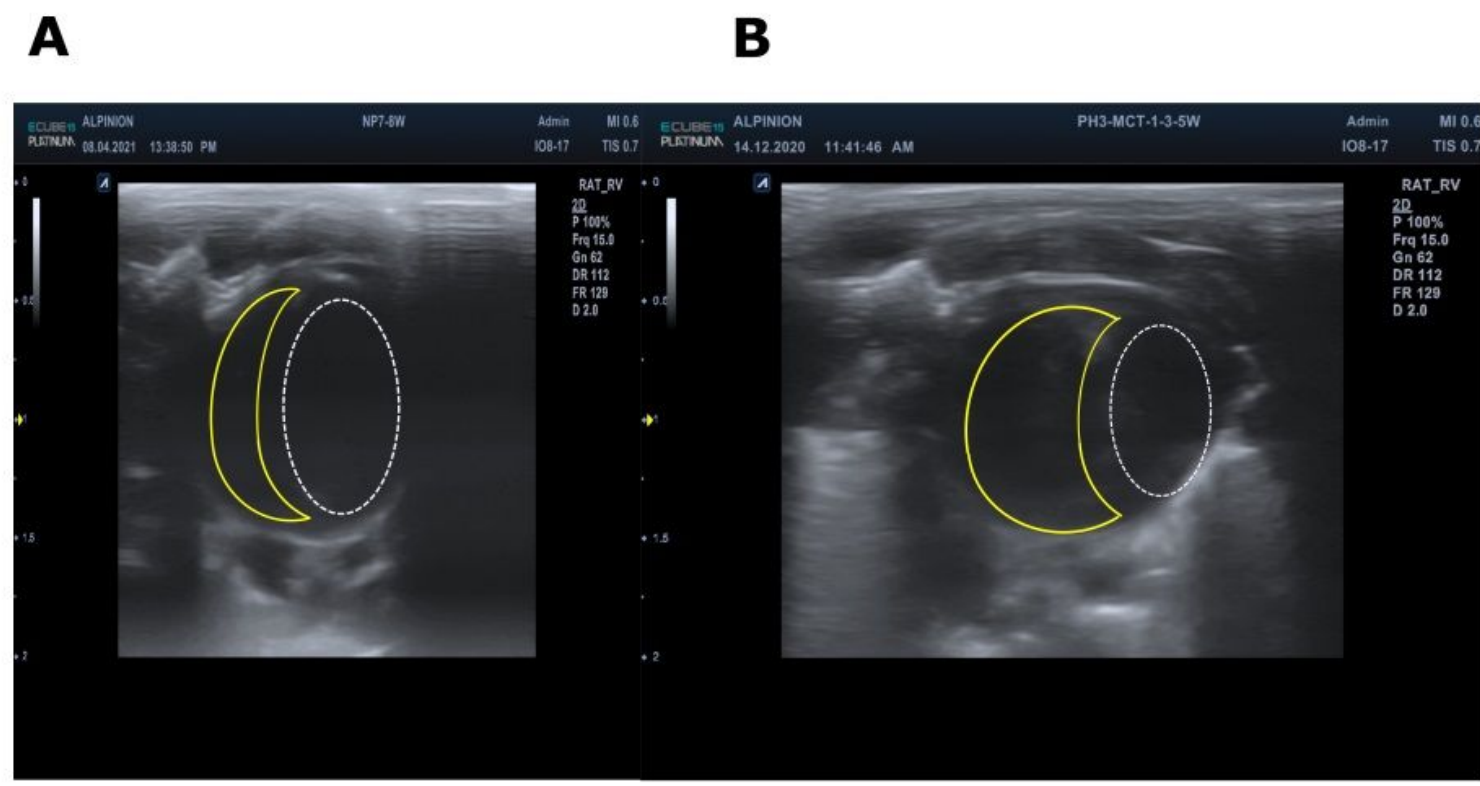

\section{C}
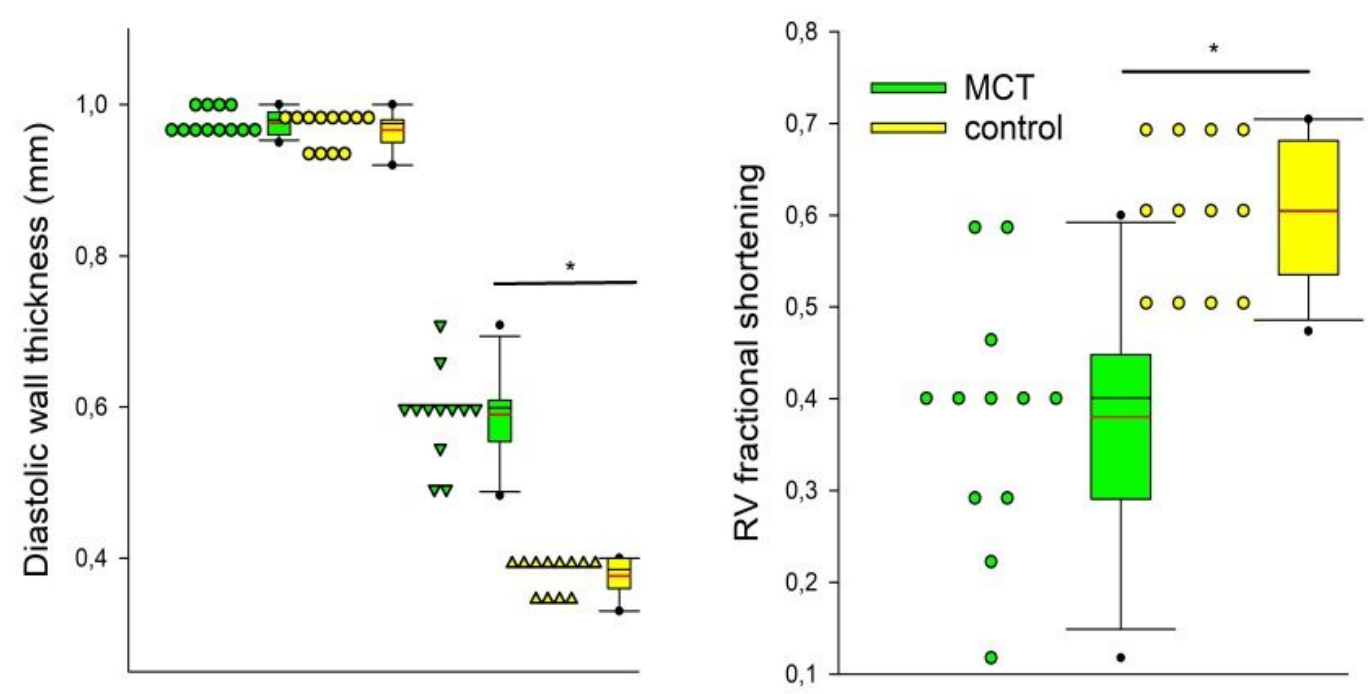

Left ventricle Right ventricle

\section{Figure 2}

Echocardiographic characterization of rats with monocrotaline-induced pulmonary hypertension and normal rats. Shortaxis view of the rat heart in control $(A)$ and monocrotaline-treated $(B)$ rats. Yellow line outlines contours of the right 
ventricle, white line of the left ventricle. Markedly dilated right ventricle and compressed left ventricle can be seen in monocrotaline-treated rats (B). Lower panels demonstrate right ventricular fractional shortening (C) and wall thickness (D). Horizontal lines represent mean (red) and median (black), the bottom and the top of the boxes represent the upper and the lower quartile, he whiskers represent 10th and 90th percentile, while the solid circles represent the individual data points. * $p<0.05$

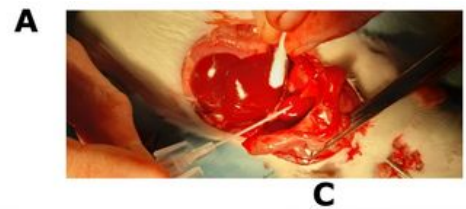

B

C
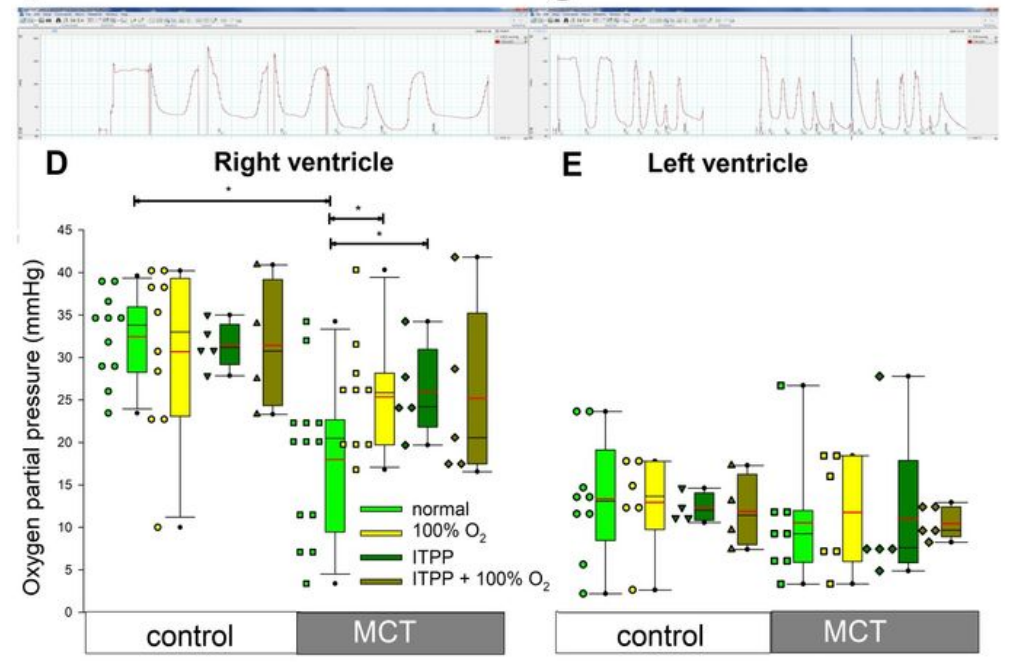

$\mathbf{F}$

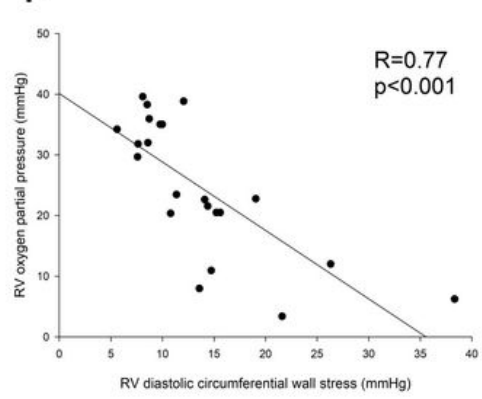

G
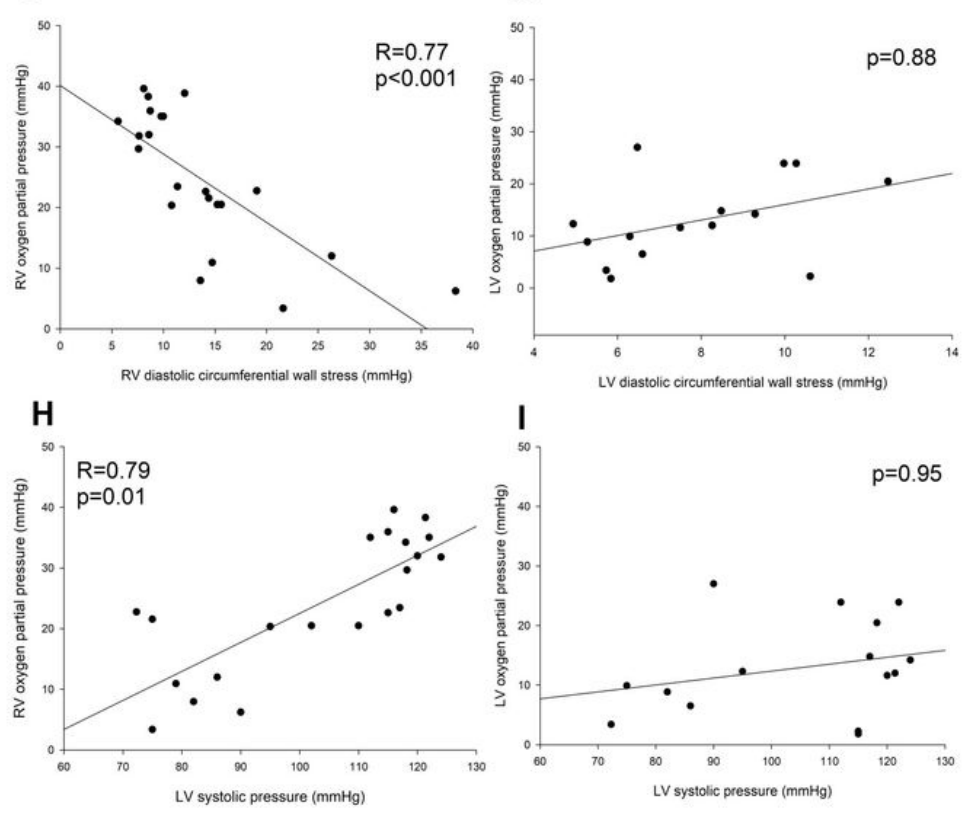

Figure 3

Measurements of myocardial oxygen tension. (A) An image demonstrating measurement of right ventricular (RV) partial oxygen pressure (p02) using a fiber-optic probe inserted into the RV, almost parallel to the epicardial surface.

Representative recordings of p02 measurements in control and monocrotaline-treated rats are presented on panels (B) and (C), respectively. The horizontal axis indicates p02. Panel B presents pO2 values measured under $30-40 \%$ inspiration oxygen (NORMAL 02), while panel B presents p02 values measured under 30-40\% inspiration oxygen (NORMAL O2) and $100 \%$ inspiration oxygen (HIGH 02). RV, right ventricle; LV, left ventricle. The results are summarized for the right and left 
ventricle on panels (D) and (E), respectively. Correlations between RV and LV pO2 and wall stress as well as LV systolic pressure are shown on panels (F) through (I). Horizontal lines represent mean (red) and median (black), the bottom and the top of the boxes represent the upper and the lower quartile, he whiskers represent 10th and 90th percentile, while the solid circles represent the individual data points. * $p<0.05$. 